\title{
VISITORS TO A BIRD FEEDER
}

\section{BILL ANAKA and JOYCE ANAKA, Box 211, Yorkton, Saskatchewan. S3N 2 V7}

We have several bird feeders in our yard every winter to satisfy our numerous feathered boarders. Two of these feeders are left out every summer to attract the occasional chickadee or woodpecker. It was some time in October 1983 that we realized the rolled oats in one feeder, set up near a large Balsam Poplar, were being consumed rapidly. This is a small enclosed feeder measuring approximately $30 \mathrm{~cm} \times 25 \times$ 20 with a glass front. It sits on a section of tree trunk 1.3 metres high. When we realized the food was disappearing overnight we presumed the nocturnal visitor was probably a mouse or vole. A mousetrap was duly placed in said feeder after dark and retrieved before sunrise. The trap was sprung and empty. This procedure was repeated several times with the same results and a continuing consumption of rolled oats.

After the first snowfall in November the mystery deepened. There were no tracks at the base of the feeder, mouse or otherwise, yet the rolled oats were being eaten every night. We know that over the years people have kidded us about living on the edge of that "Lake of the Spirits" (Good Spirit Lake), but we really didn't think the ghosts and spirits of the lake would be interested in rolled oats!

Repeated checking of the feeder with a flashlight through the kitchen window brought results a few nights later when a dark shape was observed inside the feeder. The sudden bright light did not disturb it and closer scrutiny through binoculars revealed it to be, not a ghostly figure, but a Northern Flying Squirrel. A few evenings later we observed two squirrels in the feeder. Usually only one squirrel at a time is present in the feeder but on several occasions two have fed together. Feeding times have varied from as early as 7 p.m. in November/December to midnight and later, with no set pattern except that they will feed some time during the night. Only one night throughout the entire winter was the food untouched. The addition of a few peanuts to the diet every evening appears to be much appreciated - it took the squirrels a few nights to learn how to shell them! They have also fed on suet, baking powder biscuits and brownies but draw the line at raisins. Rolled oats remains the staple diet.

This is not the first local record of the Northern Flying Squirrel. In September 1979 a dead one was found beside the box where the family cat slept. This specimen was preserved in the freezer and delivered to the Saskatchewan Museum of Natural History in Regina on 24 October 1979.

The Northern Flying Squirrel is probably not an uncommon species locally but, being nocturnal, it escapes observation. While sitting in a blind to obtain photographs of our nightly visitor it's whistled call was heard shortly before it appeared. We realized that this was a call heard here several times over the years - always at night.

Perusing back issues of the Blue Jay we found most records for this species are from the Boreal Forest Region with a scattering of reports from the parklands. Frequent comments on the sightings were to the effect that it was the first one that had been seen. And in at least two cases it was the family cat that had caught one overnight and left the specimen for identification. Sites chosen for nests were widely varied - 
from bluebird nest boxes on the Brandon line, to timber bridges at Tisdale, to the box serving as a seat in the lookout room on top of a fire tower near Glaslyn.

A search of the surrounding woods for the den tree has proven unsuccessful so far. We have tapped and knocked and pounded on literally dozens of trees with woodpecker holes in them with no results. But with an elusive species such as the "Fairy Diddle" (a popular name for all species of flying squirrels), some mystery must remain. The search for the den tree goes on. The rolled oats and peanuts continue to disappear every night.

\section{LYNX PREDATION}

HANS DE VOGEL, Box 219, Neilburg, Saskatchewan. SOM 2CO

I would like to tell you about an experience I had once. One year we decided to try and raise some ducks on our lake. Early in May we got thirtyone, day old White Peking ducklings, from the hatchery. We easily raised them in the barn under a heat lamp. When their feathers started to show we brought them to the lake, at first within a snow fence half in and half out of the water. They had a wooden feed trough and we fed them boiled braley mixed with chick starter. There were thirty then; one had gotten stepped on by a cow. After about ten days we took the snow fence away and let them go.

It was a beautiful sight to see, the white ducks spread all over the lake, until one morning they would not come for their feed. Instead they stayed in a tight bunch in the middle of the lake. I got my binoculars, stood on the hill and counted twenty-seven ducklings. The next morning the same thing and there were another four missing.
That same day after dinner, we heard crows and magpies giving alarm calls near the lake. I walked over and the same thing, a tight bunch of ducks in the middle of the lake. Only one thing was different, there was a small boy in a grey sweater sitting down beside the feed trough looking at the ducks. (That was my first impression). The small boy stood up and turned into a big long-legged Lynx. She looked straight at me with her big yellow eyes. In two bounds she was on the wooden fence that runs from the corrals to the lake. Then she turned around and looked at me again. With a sort of silent snarl, she disappeared into the water willows. I saw right away that it was a lactating female. She must have caught two or three of our ducks every day when they came to shore to feed, preen their feathers and sleep. There must have been lynx kittens in the bush nearby.

We rounded up our remaining twenty-two ducks and took them to a neighbour to raise. In the fall, they were as big as small geese. We gave a lot of them away and had roasted duck quite often that winter.

That same fall on our nearest neighbour's farm, a tame goose was killed. It was dragged into the bush, fed on and covered with snow and dried leaves. The neighbour set a trap and the next day there was a small Lynx in it. That could have been one of our Lynx kittens.

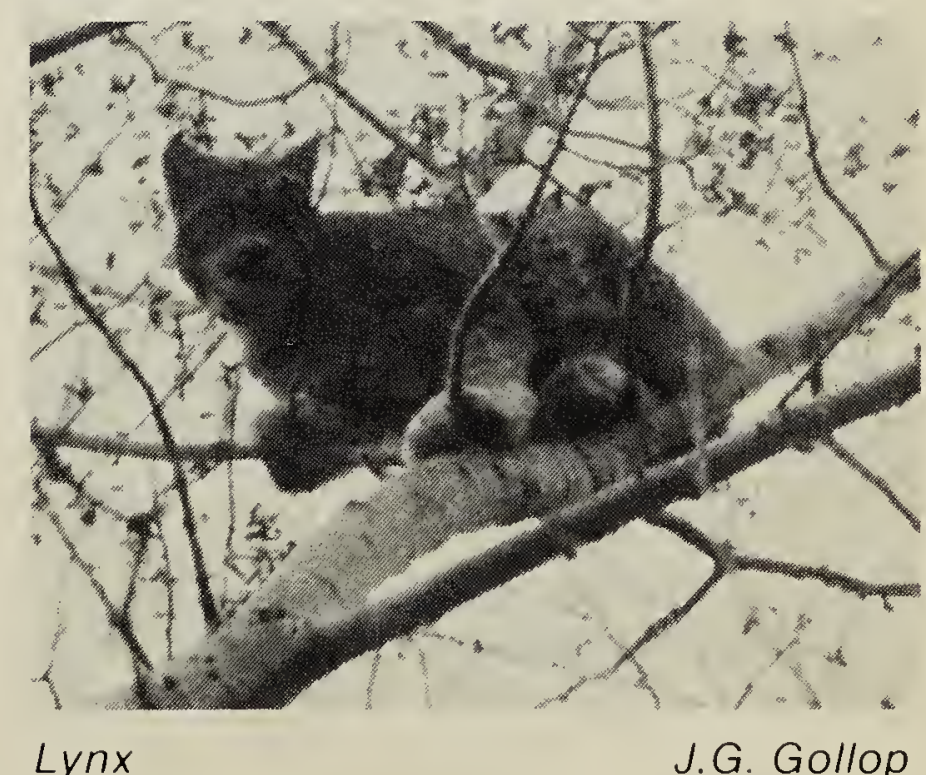

Lynx

J.G. Gollop 